\title{
Platelet-derived Growth Factor Promotes Smooth Muscle Migration and Intimal Thickening in a Rat Model of Balloon Angioplasty
}

\author{
Arkadiusz Jawien, Daniel F. Bowen-Pope, Volkhard Lindner, Stephen M. Schwartz, and Alexander W. Clowes \\ Departments of Surgery and Pathology, University of Washington School of Medicine, Seattle, Washington 98195
}

\begin{abstract}
Platelet-derived growth factor (PDGF) is a mitogen and chemoattractant for vascular smooth muscle cells (SMC) in vitro, but its activities in vivo remain largely undefined. We infused recombinant PDGF-BB (0.01-0.30 $\mathrm{mg} / \mathrm{kg}$ per $\mathrm{d}$ i.v.) into rats subjected to carotid injury. PDGF-BB produced a small increase (two- to threefold) in medial SMC proliferation. More importantly, PDGF-BB greatly increased (20-fold) the intimal thickening and the migration of SMC from the media to the intima during the first $7 \mathrm{~d}$ after injury. These data provide support for the hypothesis that PDGF, and perhaps other platelet factors, might play an important role in the movement of mesenchymal cells into zones of injury undergoing repair. (J. Clin. Invest. 1992. 89:507-511.) Key words: platelet-derived growth factor • intimal hyperplasia - arteriosclerosis - chemotaxis • mitogenesis
\end{abstract}

\section{Introduction}

Platelet-derived growth factor (PDGF) ${ }^{1}$ was originally defined by its ability to stimulate fibroblast and arterial smooth muscle cell (SMC) proliferation in vitro (1). Subsequent investigation has demonstrated that PDGF also affects a number of other cellular functions including migration (2). Nevertheless, the activities of PDGF in vivo are still unknown even under conditions of injury. The vascular response to injury is a particularly important issue because of the hypothesis implicating PDGF in SMC proliferation and the formation of the intimal lesion (3). Whether the in vitro definition of PDGF as a growth factor applies to its function in vivo in pathological states and during growth and development is not known.

Blood vessels undergoing angioplasty respond to the trauma of the catheter by a series of thrombotic and cellular events including early platelet accumulation, replication of medial SMCs, migration into the intima of replicating and non-replicating SMC into the media, and chronic replication of intimal SMC (4-6). In this study, we attempted to determine the effect of intravascularly infused PDGF on migration and proliferation of SMCs in rat carotid artery subjected to a de-endothe-

Address correspondence to Alexander W. Clowes, M.D., Department of Surgery, University of Washington School of Medicine, RF-25, Seattle, WA 98195.

Received for publication 1 July 1991 and in revised form 10 September 1991.

1. Abbreviations used in this paper: $\mathrm{PDGF}$, platelet-derived growth factor; rPDGF-BB, recombinant human PDGF-BB; SMC, smooth muscle cell.

J. Clin. Invest.

(c) The American Society for Clinical Investigation, Inc.

0021-9738/92/02/0507/05 \$2.00

Volume 89, February 1992, 507-511 lializing injury. Although PDGF can exist in three dimeric forms, PDGF-BB is a good candidate for study because it is the major isoform found in rat platelets, and human PDGF-BB is available in recombinant form (7). Moreover, the PDGF Bchain can bind to either the alpha or the beta form of the PDGF receptor, whereas the PDGF A-chain interacts only with the alpha form (8). Hence, PDGF-BB can bind to any of the highaffinity receptor dimers (beta-beta, alpha-beta, or alpha-alpha). Although mRNA for both receptor subunits is detected in normal aorta, PDGF-receptor beta subunit mRNA is much more abundant and expression is increased in the injured vessel at sites of active SMC proliferation (9). Thus, it appears likely that the response of rat arterial SMC to PDGF would be mediated through PDGF-BB binding to PDGF-receptor beta subunits.

\section{Methods}

Reagents. Recombinant human PDGF-BB (rPDGF-BB) was a gift from ZymoGenetics, Inc. (Seattle, WA). It was prepared by expression of human PDGF B-chain in the yeast Saccharomyces cerevisiae. PDGF-BB homodimers were purified to $>95 \%$ homogeneity, as assessed by amino-terminal sequencing and by SDS-PAGE under reducing or nonreducing conditions (10). The concentrations of PDGF are based on the data from amino acid analysis.

Animal model. The left carotid arteries of 3-mo-old, male, SpragueDawley rats (Simonsen Laboratories, Inc., Gilroy, CA) were denuded of endothelium by passage of either a 2-F balloon catheter or a loop of nylon filament as previously described $(6,11)$. Animals were anesthetized with $1.0 \mathrm{ml} / \mathrm{kg}$ i.m. of a solution containing acepromazine $1 \mathrm{mg} /$ ml (Fermenta Animal Health Co., Kansas City, MO), ketamine 50 $\mathrm{mg} / \mathrm{ml}$ (Aveco, Inc., Fort Dodge, IA), and rompun $5 \mathrm{mg} / \mathrm{ml}$ (Mobay Corp., Shawnee, KS) in normal saline and were cared for according to institutional guidelines. rPDGF-BB was prepared as a solution in 10 $\mathrm{mM}$ acetic acid containing $0.25 \% \mathrm{BSA}$ and infused continuously with a syringe infusion pump (Harvard Apparatus, Dedham, MA) over $6 \mathrm{~h}$ either into the aortic arch by means of a right subclavian artery catheter or into the superior vena cava through a catheter placed in the jugular vein. Control animals received an infusion of the vehicle alone. In some animals rPDGF-BB was infused intravenously by means of a miniosmotic pump (Alzet 2001; Alza Corp., Palo Alto, CA) connected to an indwelling jugular vein catheter (12) over 4 or $7 \mathrm{~d}$.

Morphology. At the end of each experiment the carotid arteries were fixed by perfusion with $4 \%$ paraformaldehyde in PBS, $\mathrm{pH} 7.4$, at $100 \mathrm{mmHg}$, embedded in Epon (two segments/animal), cross-sectioned, and stained with methylene blue. Intimal and medial cross-sectional areas were measured as described previously (13). SMC in the intimal thickening in sections of paraffin-embedded material were identified by positive staining with an antibody to SMC alpha and gamma actin (HHF 35) (14). The presence of leukocytes on the luminal surface of treated and control vessels was assessed by scanning electron microscopy.

Measurement of SMC proliferation. Tritiated thymidine (New England Nuclear, Inc., Boston, MA; $0.5 \mathrm{mCi} / \mathrm{kg}$ per dose i.p.) was administered at 8 - $\mathrm{h}$ intervals between 24 and $48 \mathrm{~h}$ after rPDGF-BB infusion. Some animals received a continuous infusion of tritiated thymidine ( 2 $\mathrm{mCi}$ in $2 \mathrm{ml}$ saline; $6.7 \mathrm{Ci} / \mathrm{mmol}$; New England Nuclear, Inc.) intraperitoneally by miniosmotic pump (Alzet $2 \mathrm{ml}$, Alza Corp.). Proliferation of intimal SMC was assessed by counting the number of labeled and unlabeled nuclei on autoradiographic preparations of histologic cross- 
sections (6). The thymidine $\left(\left[{ }^{3} \mathrm{H}\right] \mathrm{TdR}\right)$ labeling index is the fraction of labeled nuclei $\times 100$.

Measurement of SMC migration. In previously reported experiments using carotid balloon-injured rats receiving a continuous infusion of tritiated thymidine, we have shown that a population of unlabeled SMC appears in the intima (4). We have concluded that these cells must migrate from the media to the intima without dividing since all cycling cells, regardless of the number of rounds of division, become labeled with tritium. The media is the only source of SMC and no SMC are present in the intima of untraumatized vessels. Hence, a minimum estimate of SMC migration can be obtained by quantitating the number of unlabeled intimal nuclei in histological cross-sections of arteries from rats receiving a continuous intraperitoneal infusion of thymidine. This estimate is only a minimum because any cell that migrates and subsequently proliferates will not be counted. We have investigated the possibility that the apparently unlabeled cells have replicated but have incorporated less thymidine than the labeled cells. Since the labeling index is not affected by the dose or the specific activity of the infused tritiated thymidine or the autoradiographic exposure time, we are reasonably certain that the unlabeled intimal SMCs have never replicated $(4,12,15)$.

\section{Results}

Effect of $r P D G F-B B$ on intimal and medial SMC proliferation in carotid arteries subjected to balloon or filament loop denudation. Experiments were done first in rats with preexisting intimal thickening induced by balloon damage of the carotid artery since intimal SMCs express a great abundance of the PDGF-receptor beta subunit and replication is relatively low $(6,9)$. At various times after balloon injury, rPDGF-BB $(100 \mu \mathrm{g}$ in $400 \mathrm{~g}$ animals) was infused intraarterially over $6 \mathrm{~h}$ by means of a cannula placed in the aortic arch. Intimal SMC proliferation was increased two- to fourfold above control in samples retrieved from PDGF-treated animals $\geq 6$ wk after carotid injury (Fig. $1 \mathrm{~A}$ ). The labeling index was increased among the intimal SMCs, particularly those near the luminal surface, but not among medial SMCs. No significant increase in replication was seen at $2 \mathrm{wk}$, perhaps because background levels of replication were already high. These data demonstrate for the first time that infused PDGF can stimulate SMC replication.

To determine whether rPDGF-BB could also stimulate medial SMC to proliferate, rPDGF-BB (10 $\mu \mathrm{g} / \mathrm{rat})$ was infused intraarterially over $6 \mathrm{~h}$ beginning immediately after carotid injury. As expected, the thymidine labeling index in ballooned carotid arteries was elevated at $48 \mathrm{~h}$ (injured carotid: $20 \%$; uninjured carotid: $0.06 \%$ ). rPDGF-BB administration, however, produced no further increase (Fig. $1 B$ ). Since the failure to see an effect could have been due to a high background of replication, the experiment was repeated using a milder form of arterial injury $(11,16)$. When endothelium is removed completely by passage of a loop of nylon filament, the labeling index of medial SMC at $48 \mathrm{~h}$ is only slightly elevated (filament loop denudation: $1-2 \%$; balloon injury: $15-25 \%)(11,13)$. Infusion of rPDGF-BB $(10 \mu \mathrm{g} /$ rat over $6 \mathrm{~h})$ produced a two- to threefold increase in medial SMC proliferation at $48 \mathrm{~h}$ after filament loop denudation (Fig. $1 \mathrm{~B}$ ). The same effect could be achieved whether rPDGF-BB was given intraarterially or intravenously over $6 \mathrm{~h}$ (intraarterial: $4.0 \pm 0.9 \%$; intravenous: $2.7 \pm 0.4 \%$ ). There was a slight dose response, with the maximum being at $10 \mu$ g i.a. over $6 \mathrm{~h}$ (control: $1.2 \pm 0.4 \% ; 1 \mu \mathrm{g}$ i.a.: $1.2 \pm 0.4 \% ; 10 \mu \mathrm{g}$ i.a.: $4.0 \pm 0.9 \%$; $30 \mu$ g i.a.: $2.0 \pm 1.1 \%$; $100 \mu$ g i.a.: $2.2 \pm 0.8 \%$ ). Although infusion of rPDGF-BB for $6 \mathrm{~h}$ increased SMC prolif-
A

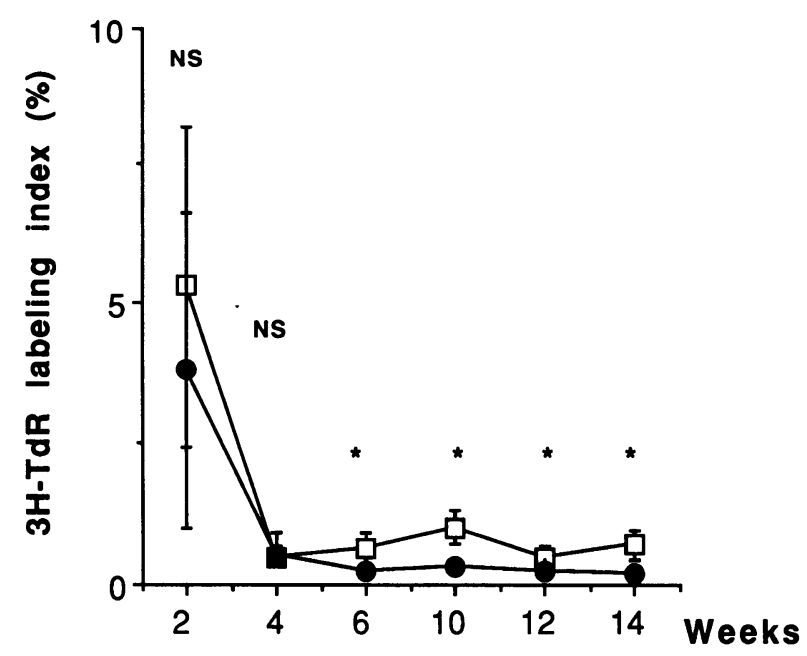

$\mathbf{B}$

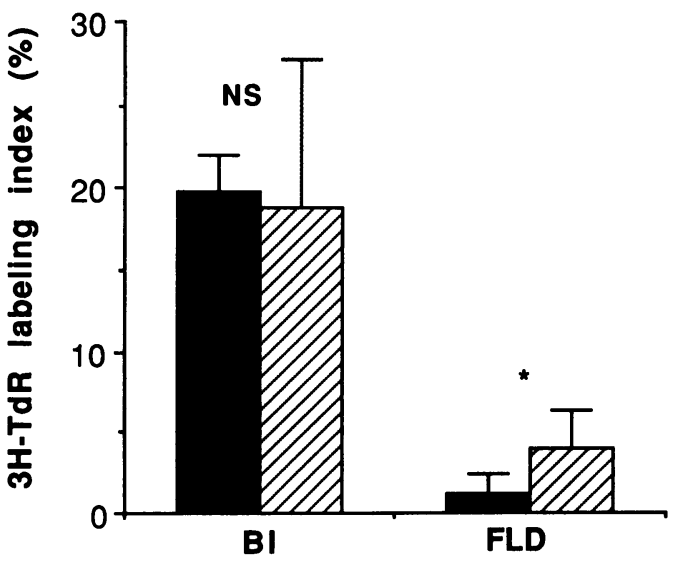

Figure 1. Effect of rPDGF-BB on SMC proliferation in injured rat carotid artery. $(A)$ Proliferation of intimal SMC in balloon-injured left carotid arteries of rats infused intraarterially for $6 \mathrm{~h}$ with either rPDGF-BB $(100 \mu \mathrm{g} / \mathrm{rat})$ or vehicle (control). The thymidine (3HTdR) labeling index is the fraction of labeled nuclei (mean $\% \pm S E ; n$ $=5 /$ group $\left.;{ }^{*} P<0.05\right) .-\square-$, PDGF; $-\bullet-$, Control. $(B)$ Proliferation of medial SMC in left carotid arteries denuded either by passage of a balloon catheter $(B I)$ or a loop of nylon wire (filament loop denudation: $F L D)$. rPDGF-BB $(10 \mu \mathrm{g} / \mathrm{rat})$ was infused intraarterially over $6 \mathrm{~h}$ beginning at the time of injury, and the thymidine labeling

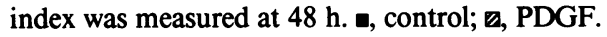

eration, it had no effect on platelet or leukocyte accumulation on the luminal surface of the injured vessels at $48 \mathrm{~h}$ and did not alter intimal thickening at $14 \mathrm{~d}$.

In summary, infused rPDGF-BB is able to stimulate replication of both medial and intimal SMC, although the net effect at the doses studied was modest.

$r P D G F-B B$ stimulates $S M C$ migration from the media to the intima. One of the advantages of the rat model is its simplicity. There are no SMCs in the intima of normal, untraumatized rat carotid artery; before an intimal lesion can develop, SMCs must migrate from the media to the intima through gaps in the internal elastic lamina. Since the accumulation of SMC in the intima is the consequence of both migration and subsequent 
A
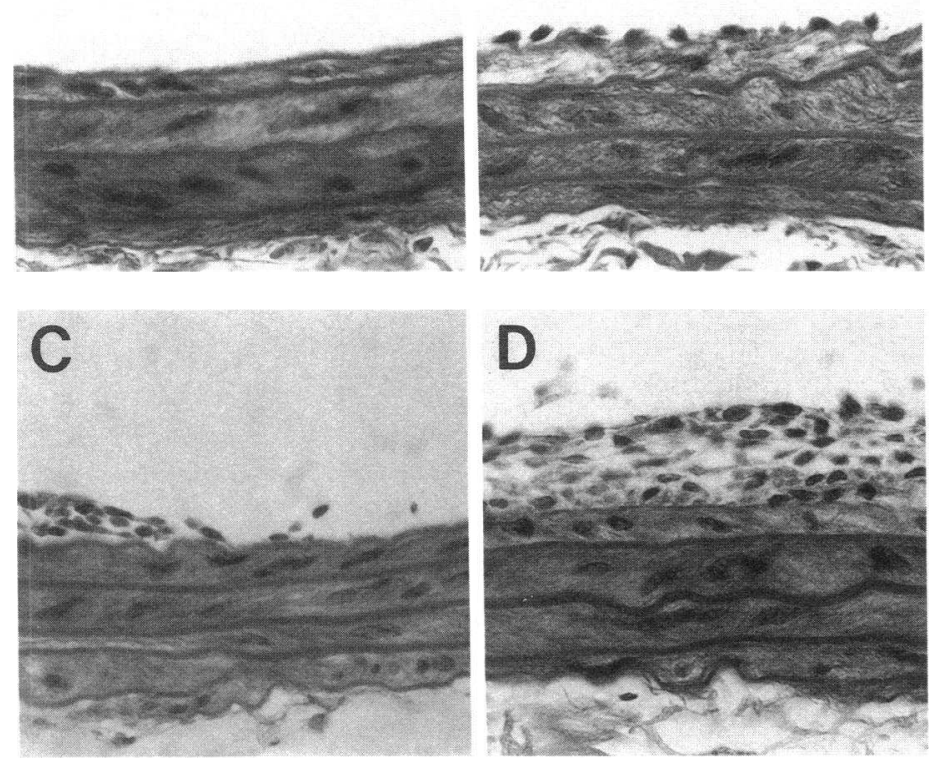

Figure 2. Histologic cross-section demonstrating the effect of chronic intravenous infusions of rPDGF-BB on intimal thickening in injured rat carotid arteries. Endothelium was stripped away with a nylon loop (filament loop denudation). rPDGF-BB $(0.10 \mathrm{mg} / \mathrm{kg}$ per d) $(B$ and $D)$ or carrier medium alone (controls: $A$ and $C$ ) was infused continuously intravenously by means of a miniosmotic pump connected to an indwelling jugular venous catheter and the vessels retrieved at $4(A$ and $B)$ or $7(C$ and $D)$ $d$. SMCs were evident on the luminal surface at $4 \mathrm{~d}$ and had formed a substantial intimal thickening by $7 \mathrm{~d}$ in the arteries of PDGF-treated animals. intimal proliferation, it is difficult to obtain a quantitative measure of migration alone. As described in Methods, we have developed an assay that provides a minimum estimate of SMC migration by making use of the observation that some SMC migrate into the intima without entering the cell cycle (4). SMC migration can thus be estimated by measuring the number of unlabeled intimal cells per cross-section in injured arteries of animals receiving a continuous infusion of tritiated thymidine. Under such circumstances, SMCs that undergo one or more rounds of division are labeled with thymidine and can be unambiguously identified on tissue sections (4). Beginning at the time of injury, rPDGF-BB $(0.01-0.30 \mathrm{mg} / \mathrm{kg}$ per d) was administered intravenously and the tritiated thymidine intraperitoneally from separate miniosmotic pumps. At $4 \mathrm{~d}$ the intima of control vessels injured by filament loop denudation contained no cells and at $7 \mathrm{~d}$ only focal accumulations of SMCs (Fig. 2, $A$ and $C$ ). At $4 \mathrm{~d}$ in rats receiving rPDGF-BB, the intima of carotid arteries contained a monolayer of SMC and at $7 \mathrm{~d}$ was markedly thickened (Fig. 2, $B$ and $D$ ). The number of unlabeled intimal nuclei was greatly increased in rats receiving rPDGF-BB (Fig. $3 A$ and Table I). These unlabeled cells had migrated without replicating. The number of labeled nuclei was also increased, but only in proportion to the number of unlabeled cells (Fig. $3 \mathrm{~A}$ ).

The cumulative labeling index of the intimal SMC over $7 \mathrm{~d}$ was not affected by the rPDGF-BB infusion (Fig. $3 \mathrm{~B}$ ). On the other hand, the cumulative labeling index for the medial SMC increased two- to fivefold. This observation is consisterit with the small increase in pulse thymidine labeling index observed at $48 \mathrm{~h}$ after filament loop denudation and a 6-h infusion of PDGF (Fig. $1 B$ ).

The rPDGF-BB infusion did not increase the thymidine labeling index or induce migration of SMC in normal, untraumatized carotid arteries.

\section{Discussion}

Since platelets adhere, spread, and degranulate on the denuded artery within seconds after injury, platelet granule contents, including PDGF-BB, have been posited to play a significant role in the subsequent migration and proliferation of SMC and the formation of intimal thickening (3). Intimal thickening is diminished if the animals are made thrombocytopenic $(17,18)$. However, early gene expression and the initial proliferative response of medial SMCs after balloon injury are not affected by the lack of platelets (18). Moreover, we could find only a modest effect of infused rPDGF-BB on the extent of SMC replication in the period immediately after injury. Under similar circumstances, basic fibroblast growth factor, which is not found in platelets and is released from injured SMCs, produces a dramatic stimulation of medial SMC replication $(19,20)$. These results raise the possibility that PDGF and other platelet factors have little effect on the initial proliferative response of medial SMC but might affect migration or subsequent proliferation in the intima.

The data in the present study demonstrate that the infusion of rPDGF-BB increased SMC replication and migration. The data also suggest that migration may account for most of the effect of rPDGF-BB on intimal thickening and that once the SMC are in the intima they undergo a similar number of divisions, regardless of the presence or absence of infused rPDGFBB. This interpretation arises from three sources. First, in a detailed analysis of the kinetics of SMC replication after balloon injury (4), we found that although proliferation was important a substantial portion of intimal accumulation of SMCs depended on migration. Second, in vitro studies from our laboratories have shown that SMCs from the neointima have altered proliferative capacities, including the ability to proliferate independently of exogenous PDGF $(21,22)$. Third, in the pres- 


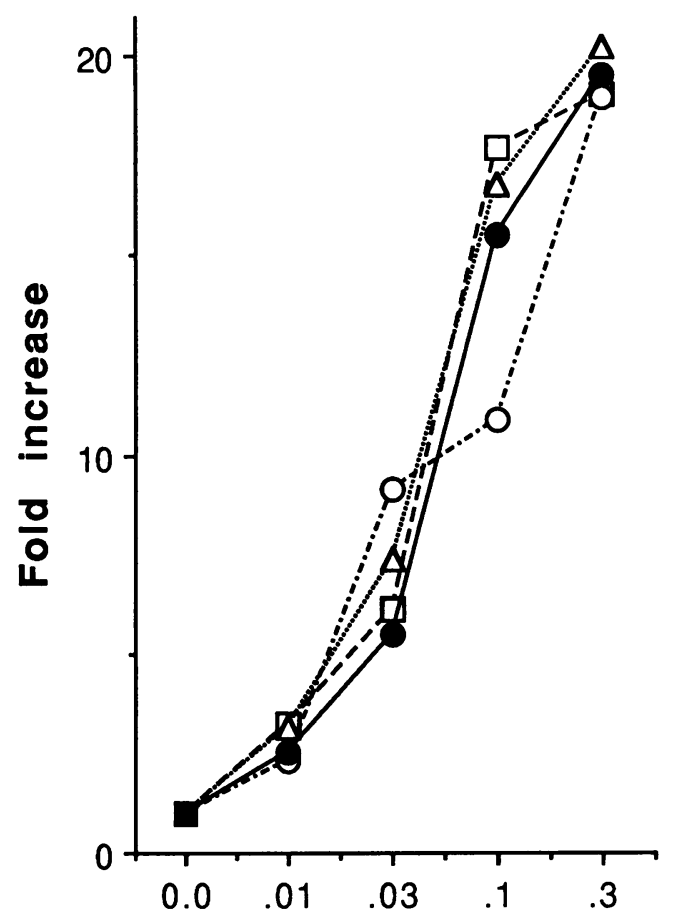

rPDGF-BB $(\mathrm{mg} / \mathrm{kg} / \mathrm{d})$

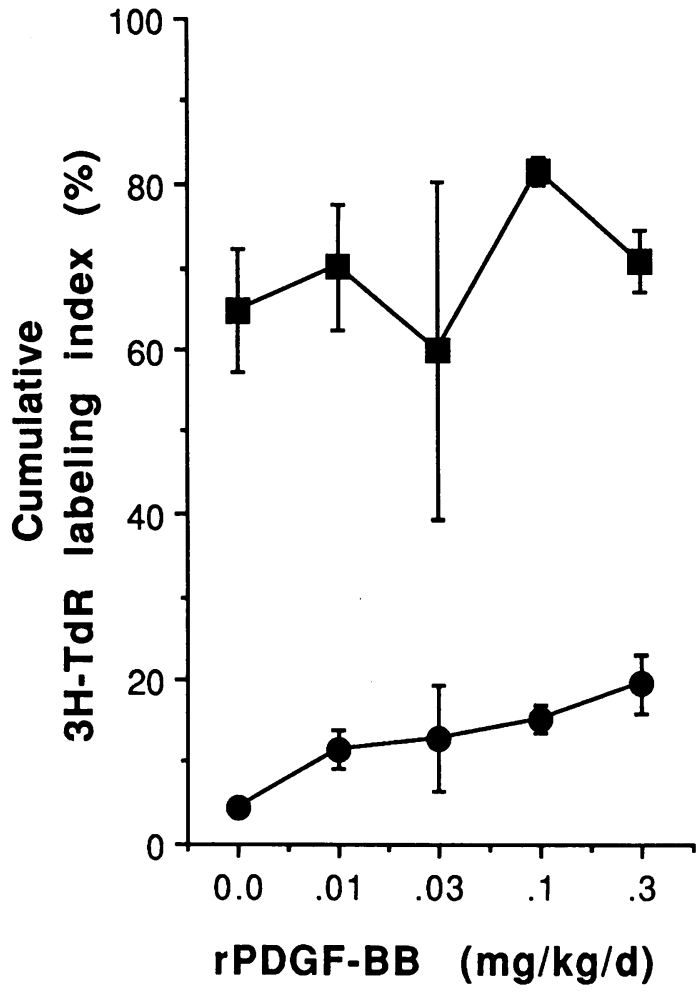

Figure 3. Effect of rPDGF-BB on intimal area, intimal SMC number, and cumulative thymidine labeling (3H-TdR) index in rat carotid arteries at $7 \mathrm{~d}$ after filament loop denudation. The experiments were conducted as described in Fig. 2 except that the dose of rPDGF-BB varied between 0 and $0.30 \mathrm{mg} / \mathrm{kg}$ per d i.v. All animals received a continuous infusion of tritiated thymidine intraperitoneally by miniosmotic pump. $(A)$ Intimal area and number of labeled and unlabeled intimal cells (fold increase over control). $--\square--$, labeled cells; $. . .0 \cdots . .$, , unlabeled cells; $\cdots \cdots \Delta \cdots$, , total cells; $-\bullet-$, intimal area. $(B)$ Cumulative thymidine labeling index $(\%)$ in the media and the intima. $n=5$ animals in each group. $-\square-$, intima; $-\bullet-$, media.

ent study we find that the dose-dependent increase in intimal cell number or mass is directly proportional to the increase in cell migration (Fig. 3). The simplest interpretation of these data is that most of the effect of infused rPDGF-BB is on migration followed by a number of divisions in the intima that may be largely independent of the infused growth factor.

This interpretation is further supported by a recent study by Ferns et al. (23). These experiments used nude rats treated with high doses of a polyclonal antibody to human platelet PDGF (which cross-reacts with rat platelet PDGF) and subjected to balloon injury of the carotid artery. They observed a $40 \%$ reduction in intimal thickening, but no change in thymidine labeling index, at $8 \mathrm{~d}$ after surgery. These findings are consistent with our own and support the conclusion that platelet PDGF may play an important role in SMC migration.

The factors responsible for intimal SMC proliferation have not been defined. Early on (e.g., 7-14 d), it is quite possible that various mitogens, including PDGF-BB from platelets (7) or PDGF from the SMCs themselves, maximally stimulate intimal SMC replication (9). Infusion of rPDGF-BB would then be

Table 1. Effect of rPDGF-BB on Intimal Area and Intimal Cell Number

\begin{tabular}{lccccc}
\hline & \multicolumn{5}{c}{ rPDGF-BB dose (mg/kg per d) } \\
\cline { 2 - 6 } & 0 & 0.01 & 0.03 & 0.10 & 0.30 \\
\hline Intimal Area ( (m) $^{2}$ ) & $0.002 \pm 0.001$ & $0.005 \pm 0.005$ & $0.011 \pm 0.002$ & $0.031 \pm 0.009$ & $0.039 \pm 0.005^{*}$ \\
Labeled SMC (nuclei/section) & $7.3 \pm 5.0$ & $23.6 \pm 22.1$ & $44.5 \pm 16.9$ & $129.0 \pm 38.0^{*}$ & $139.0 \pm 25.0^{*}$ \\
Unlabeled SMC (nuclei/section) & $2.9 \pm 1.8$ & $6.6 \pm 6.0$ & $26.1 \pm 10.9$ & $31.1 \pm 10.6$ & $54.1 \pm 3.5^{*}$ \\
\hline
\end{tabular}

Values are mean $\pm \mathrm{SE} ; n=5$ animals/group.

* $P<0.05$ vs. control (Kruskal-Wallis 1-way analysis of variance with Dunn's correction for multiple comparisons).

rPDGF-BB, recombinant human platelet-derived growth factor, SMC, smooth muscle cells. 
expected to have no effect. On the other hand, we observed that intimal SMC at late times after injury ( $>1 \mathrm{mo}$ ) replicate in response to infused rPDGF-BB. This finding might mean that endogenous sources of PDGF had decreased on account of decreased platelet accumulation or SMC synthesis of growth factors.

Certain caveats should be expressed about these conclusions. First, as with any in vivo pharmacological study, the effects of the infused material may represent a direct or indirect action of PDGF on the cells under study. As noted earlier, the SMCs possess the receptors for PDGF and hence could respond directly to the infused PDGF-BB. It is also possible that PDGF could stimulate leukocyte invasion of the injured artery and that these cells would then produce factors to influence SMC function $(24,25)$. However, no increase in leukocyte adherence and accumulation was noted. Second, it is premature to extend any of these results to atherosclerosis or restenosis in the human atherosclerotic vessel after surgical manipulation. Those processes may be much more complex because of the mixture of inflammatory cells in the pathologic tissue, the effects of multiple or prolonged thrombotic episodes, or the unusual properties of the intimal SMC themselves $(9,21,26-30)$.

In summary, these data represent the first evidence that PDGF can have mitogenic and chemotactic effects for SMCs in vivo. The data also suggest that the chemotactic effect may be more important than the mitogenic effect in the formation of the neointima after injury of the rat carotid artery.

\section{Acknowledgments}

The authors gratefully acknowledge the assistance of Selina Vergel and Thomas Kirkman in the conduct of the experiments.

These studies were supported by grants HL-42270 and GM-35501 from the National Institutes of Health.

\section{References}

1. Ross, R., J. Glomset, B. Kariya, and L. Harker. 1974. A platelet-dependent serum factor that stimulates the proliferation of arterial smooth muscle cells in vitro. Proc. Natl. Acad. Sci. USA. 71:1207-1210.

2. Raines, E. W., D. F. Bowen-Pope, and R. Ross. 1989. Platelet-derived growth factor. In Handbook of Experimental Pharmacology: Peptide Growth Factors and Their Receptors. Springer-Verlag, Heidelberg. 173-232.

3. Ross, R., and J. A. Glomset. 1976. The pathogenesis of atherosclerosis. $N$ Engl. J. Med. 295:369-377;420-425.

4. Clowes, A. W., and S. M. Schwartz. 1985. Significance of quiescent smooth muscle migration in the injured rat carotid artery. Circ. Res. 56:139-145.

5. Clowes, A. W., M. M. Clowes, and M. A. Reidy. 1986. Kinetics of cellular proliferation after arterial injury. III. Endothelial and smooth muscle growth in chronically denuded vessels. Lab. Invest. 54:295-303.

6. Clowes, A. W., M. A. Reidy, and M. M. Clowes. 1983. Kinetics of cellular proliferation after arterial injury. I. Smooth muscle growth in the absence of endothelium. Lab. Invest. 49:327-333.

7. Bowen-Pope, D. F., C. E. Hart, and R. A. Seifert. 1989. Sera and conditioned media contain different isoforms of platelet-derived growth factor (PDGF) which bind to different classes of PDGF receptor. J. Biol. Chem. 264:2502-2508.

8. Seifert, R. A., C. E. Hart, P. E. Phillips, J. W. Forstrom, R. Ross, M. J. Murray, and D. F. Bowen-Pope. 1989. Two different subunits associate to create isoform-specific platelet-derived growth factor receptors. J. Biol. Chem. 264:8771-8778.
9. Majesky, M. W., M. A. Reidy, D. F. Bowen-Pope, C. E. Hart, J. N. Wilcox, and S. M. Schwartz. 1990. PDGF ligand and receptor gene expression during repair of arterial injury. J. Cell Biol. 111:2149-2158.

10. Hart, C. E., J. W. Forstrom, J. D. Kelly, R. A. Seifert, R. A. Smith, R. Ross, M. J. Murray, and D. F. Bowen-Pope. 1988. Two classes of PDGF receptor recognize different isoforms of PDGF. Science (Wash. DC). 240:1529-1531.

11. Lindner, V., M. A. Reidy, and J. Fingerle. 1989. Regrowth of arteria endothelium. Denudation with minimal trauma leads to complete endothelia cell regrowth. Lab. Invest. 61:556-563.

12. Clowes, A. W., and M. M. Clowes. 1986. Kinetics of cellular proliferation after arterial injury. IV. Heparin inhibits rat smooth muscle mitogenesis and migration. Circ. Res. 58:839-845.

13. Clowes, A. W., M. A. Reidy, and M. M. Clowes. 1983. Mechanisms of stenosis after arterial injury. Lab. Invest. 49:208-215.

14. Tsukada, T., D. Tippens, D. Gordon, R. Ross, and A. M. Gown. 1987. HHF-35, a muscle-actin-specific monoclonal antibody. Am. J. Pathol. 126:5160.

15. Lombardi, D. M., M. A. Reidy, and S. M. Schwartz. 1991. Methodologic considerations important in the accurate quantitation of aortic smooth muscle cell replication in the normal rat. Am. J. Pathol. 138:441-446.

16. Fingerle, J., Y. P. T. Au, A. W. Clowes, and M. A. Reidy. 1990. Intimal lesion formation in rat carotid arteries after endothelial denudation in absence of medial injury. Arteriosclerosis. 10:1082-1087.

17. Friedman, R. J., M. B. Stemerman, B. Wenz, S. Moore, J. Gauldie, M. Gent, M. L. Tiell, and T. H. Spaet. 1977. The effect of thrombocytopenia on experimental atherosclerotic lesion formation in rabbits. Smooth muscle cell proliferation and re-endothelialization. J. Clin. Invest. 60:1191-1201.

18. Fingerle, J., R. Johnson, A. W. Clowes, M. W. Majesky, and M. A. Reidy. 1989. Role of platelets in smooth muscle cell proliferation and migration after vascular injury in rat carotid artery. Proc. Natl. Acad. Sci. USA. 86:8412-8416.

19. Lindner, V., D. A. Lappi, A. Baird, R. A. Majack, and M. A. Reidy. 1991. Role of basic fibroblast growth factor in vascular lesion formation. Circ. Res. 68:106-113

20. Lindner, V., and M. A. Reidy. 1991. Proliferation of smooth muscle cells after vascular injury is inhibited by an antibody against basic fibroblast growth factor. Proc. Natl. Acad. Sci. USA. 88:3739-3743.

21. Walker, L. N., D. F. Bowen-Pope, and M. A. Reidy. 1986. Production of platelet-derived growth factor-like molecules by cultured arterial smooth muscle cells accompanies proliferation after arterial injury. Proc. Natl. Acad. Sci. USA. 83:7311-7315.

22. Schwartz, S. M., L. Foy, D. F. Bowen-Pope, and R. Ross. 1990. Derivation and properties of platelet-derived growth factor-independent rat smooth muscle cells. Am. J. Pathol. 136:1417-1428.

23. Ferns, G. A. A., E. W. Raines, K. H. Sprugel, A. S. Motani, M. A. Reidy, and R. Ross. 1991. Inhibition of neointimal smooth muscle accumulation after angioplasty by an antibody to PDGF. Science (Wash. DC). 253:1129-1132.

24. Siegbahn, A., A. Hammacher, B. Westermark, and C.-H. Heldin. 1990 Differential effects of the various isoforms of platelet-derived growth factor on chemotaxis of fibroblasts, monocytes, and granulocytes. J. Clin. Invest. 85:916920.

25. Deuel, T. F., R. M. Senior, J. S. Huang, and G. L. Griffin. 1982. Chemotaxis of monocytes and neutrophils to platelet-derived growth factor. J. Clin. Invest. 69:1046-1049.

26. Dartsch, P. C., G. Bauriedel, I. Schinko, H.-D. Weiss, B. Höfling, and E. Betz. 1989. Cell constitution and characteristics of human atherosclerotic plaques selectively removed by percutaneous atherectomy. Atherosclerosis. 80:149-157.

27. Birinyi, L. K., S. J. C. Warner, R. N. Salomon, A. D. Callow, and P. Libby. 1989. Observations on human smooth muscle cell cultures from hyperplastic lesions of prosthetic bypass grafts: production of a platelet-derived growth factorlike mitogen and expression of a gene for platelet-derived growth factor receptor -a preliminary study. J. Vasc. Surg. 10:157-165.

28. Wilcox, J. N., K. M. Smith, L. T. Williams, S. M. Schwartz, and D. Gordon. 1988. Platelet-derived growth factor mRNA detection in human atherosclerotic plaques by in situ hybridization. J. Clin. Invest. 82:1134-1143.

29. Gordon, D., M. A. Reidy, E. P. Benditt, and S. M. Schwartz. 1990. Cell proliferation in human coronary arteries. Proc. Natl. Acad. Sci. USA. 87:4600 4604.

30. Libby, P., S. J. Warner, R. N. Salmon, and L. K. Birinyi. 1988. Production of platelet-derived growth factor-like mitogen by smooth muscle cells from human atheroma. N. Engl. J. Med. 318:1493-1498. 